\title{
Biosseguridade na produção de suínos
}

\author{
Biosecurity in the production of swine
}

\section{Rafael Massotti", Danni Maisa da Silva, Robson Bohrer, Divanilde Guerra, Eduardo Lorensi de Souza e Ramiro Pereira Bisognin}

Recebido em 18/07/2015 / Aceito em 10/01/2017

\section{RESUMO}

A suinocultura vem se destacando mundialmente nos últimos anos. No Brasil a produção de suínos merece destaque em termos de crescimento devido principalmente as mudanças nos sistemas de criação. Com o modelo de integração, os produtores passaram a ter maiores aportes e orientações técnicas, bem como uma venda pré-estabelecida com a empresa integradora. Com isso, a produção de suínos desenvolveu-se rapidamente nos três Estados do Sul (Paraná, Santa Catarina e Rio Grande do Sul) que possuem os maiores rebanhos de suínos do País. Este trabalho teve como objetivo avaliar a situação atual das unidades produtoras de leitões da região Noroeste do Rio Grande do Sul acerca dos principais itens que compõem o programa de biosseguridade, identificando pontos críticos e elencando oportunidades de melhoria. A metodologia adotada consistiu na aplicação de questionário semiestruturado e visitas às propriedades dos produtores integrados. Com os resultados, observou-se que 27,3\% das granjas são Unidades Produtoras de Leitões Desmamados, e 72,7\% são Unidades Produtoras de Leitões Descrechados. Com relação ao cercamento, $72,6 \%$ das granjas atenderam ao quesito, outro item apontado foi o acesso a água para dessedentação animal, onde $54,5 \%$ possuem acesso por via de poço artesiano. A maioria das unidades estudadas atingiu os objetivos e normas de biosseguridade, garantindo assim a sanidade e qualidade da carne suína produzida, mas também se observaram oportunidades de melhorias em relação a alguns quesitos, destacandose entre estes o cercamento, a cloração de água para dessedentação animal, a localização das lagoas de tratamento e os aspectos relacionados à descarga e carga de animais.

PALAVRAS CHAVE: carne, produtores, qualidade, sanidade, suinocultura.

\section{ABSTRACT}

The pig farming has been highlighted globally over the last few years. In Brazil the production of swine deserves to be recognized in growth terms owed mainly the changes in the breeding systems. With the integration model, the producers started to have greater contribution and technical orientation, as well as a pre-established sale with the integrating company. As a result, swine production developed rapidly in three southern states (Paraná, Santa Catarina and Rio Grande do Sul) that have the largest swine herds in the country. This work had as an objective the current situation of piglets production units the northwestern region of Rio Grande do Sul the main items that make up the biosecurity program, identifying critical points and listing opportunities to improve the process. The adopted methodology consisted of the application of semi structured questionnaire and visiting the properties of the integrated producers. As a result, it was observed that $(27.3 \%)$ of the farms produce Weaned Pigs, and $(72.7 \%)$ are units producing pigs without day care. Regarding the enclosure, where $72.6 \%$ of the farms answered the question, another item was the access to water for animal watering, where $54.5 \%$ have access via an artesian well. Most of the units studied reached the objectives and standards of biosafety, thus guaranteeing the health and quality of the pork produced, but there were also opportunities for improvements in relation to some of the requirements, among which the enclosure, chlorination of water for Animal welfare, the location of treatment lagoons and aspects related to the discharge and loading of animals.

KEYWORDS: pork, producers, quality, sanitation, pig farming.

Universidade Estadual do Rio Grande do Sul, Três Passos, RS, Brasil.

*Autor para correspondência <rafaelmassotti@gmail.com> 


\section{INTRODUÇÃO}

Segundo a Organização das Nações Unidas para Alimentação e a Agricultura - FAO (2015), a produção mundial total de carnes em 2014 foi de 311,8 milhões de toneladas, tendo a carne suína contribuído com 115,5 milhões de toneladas. O Brasil atualmente é o quarto maior produtor e exportador da carne suína e, o Rio Grande do Sul (RS) é responsável por $21 \%$ desta produção (IBGE 2012). No RS, 70\% dos suínos confinados encontram-se em regime de integração e, $74,5 \%$ das unidades produtoras de leitão (UPLs) encontram-se na Região Noroeste do Estado (POETA et al. 2014). Assim, as atividades suinícolas, nos últimos anos têm passado por inúmeras e intensas mudanças, principalmente no que diz respeito ao aumento de escala, as modernizações tecnológicas e a concentração da produção em determinadas regiões (BARCELLOS et al. 2008).

Nas últimas décadas, o Brasil apresentou um crescimento no setor agropecuário devido a diversos fatores, tais como as melhorias genéticas e estruturais, bem como a expansão da fronteira agrícola. Isso levou o país a ser uma das dez maiores economias mundiais sendo que as exportações agrícolas e das indústrias agroalimentares correspondem por $36 \%$ destas operações (OCDE-FAO 2015). Este aumento de concentração de animais resultou em uma maior pressão sobre a sanidade animal, acarretando no surgimento de doenças transmissíveis, associados ao alto grau de vulnerabilidade das granjas. Contudo, este problema pode ser minimizado através da adoção de um bom programa de biosseguridade (MAROTO MARTÍN et al. 2010), pois problemas sanitários geralmente impactam sobre os indicadores produtivos e reduzem a disponibilidade do produto final.

O contínuo crescimento populacional mundial associado ao exacerbante preço da proteína bovina tem alavancado as vendas de produtos à base de carnes e/ou cortes substitutos, principalmente de suínos devido ao seu custo-benefício (BRANDÃO 2013). $\mathrm{O}$ atendimento a novos mercados está associado às exigentes e constantes melhorias das Boas Práticas de Produção (BPP), necessitando de garantias sobre a segurança alimentar, preconizada pelo público consumidor (SONCINI \& SCHEID 2008). De acordo com a FAO (2015), Segurança Alimentar é: “o acesso de todas as pessoas, durante todo o tempo, a alimentos suficientes, seguros e nutritivos que possam satisfazer as necessidades nutricionais e alimentares para uma vida ativa e saudável". Desta forma, os planos de biosseguridade, significam um controle dos fatores envolvidos na transmissão de patógenos (OBERLENDER et al. 2013, MASCARENHAS et al. 2015). A Biosseguridade pode ser entendida como medidas protetivas que visam minimizar o risco de introdução de doenças às granjas, através da eliminação de riscos inerentes a saúde dos animais, do meio ambiente ou a qualidade dos trabalhos desenvolvidos (BORGES et al. 2011).

Nos últimos anos grandes mudanças marcaram a atividade suinícola no país, principalmente pelo acréscimo dos custos de produção, juntamente com a desvalorização do produto, além da necessidade de adaptação das instalações (MASCARENHAS et al. 2015). Neste cenário as empresas integradoras passaram a ter papel fundamental, alicerçando o crescimento de escala no setor (MIELE \& WAQUIL 2007). De acordo com BORGES et al. (2011) o plano de biosseguridade é de suma importância no controle de entrada de doenças, sendo necessário avaliar as características individuais, como localização, sistema de produção, orçamento disponível, escala e condição estrutural.

Neste contexto, acredita-se que a maior parte das UPLs atualmente estejam trabalhando em desacordo com os critérios mínimos de atendimento de parâmetros de biosseguridade animal. Para verificar esta hipótese, o presente trabalho teve por objetivo avaliar a situação atual das unidades produtoras de leitões acerca dos principais itens que compõem o programa de biosseguridade, identificando pontos críticos e elencando oportunidades de melhoria para o processo na Região Noroeste do Rio Grande do Sul.

\section{MATERIAL E MÉTODOS}

\section{Unidades Produtoras de Leitões}

O presente estudo foi realizado no período de agosto a outubro de 2015 em 22 unidades produtoras de leitões (granjas), distribuídas em 14 municípios da Região Noroeste do Estado do Rio Grande do Sul, sendo eles: Ajuricaba, Cerro Largo, Crissiumal, Doutor Maurício Cardoso, Humaitá, Nova Candelária, Pejuçara, Santa Rosa, Santo Cristo, São Martinho, São Paulo das Missões, São Pedro do Butiá, Três Passos e Tucunduva.

Nestas unidades produtivas existe a relação comercial (integração) com uma empresa de grande porte em regime de trabalho de parceria. As granjas 
variam de 0 até 2.800 matrizes alojadas, representando a introdução mensalmente de 50.000 leitões nas unidades terminadoras. As unidades possuem apoio por parte da empresa, recebendo desde matrizes, alimentação, vacinas/medicamentos, transporte e assistência técnica, cabendo ao produtor integrado o dispêndio com a estrutura da granja, mão de obra, água, luz e equipamentos para condução da atividade.

\section{Análise realizada: Questionário}

Para obtenção dos dados desta pesquisa foi aplicado um questionário semi-estruturado, nas 22 unidades produtoras de leitões, embasado pelos níveis de Biosseguridade estabelecidos pela Instrução Normativa n.19 (MAPA 2002), abordando dados desde: identificação das propriedades, capacidade produtiva, isolamento, práticas de desinfecção, sistema de tratamento de efluentes junto com o acompanhamento das atividades das granjas, de modo a proporcionar a obtenção de informações e caracterizar o atendimento das principais premissas de Biosseguridade na produção de suínos.

Comos resultados obtidos, esses foram tabelados e dispostos e trabalhados no Programa MICROSOFT EXCEL 2007, onde foram confeccionadas as tabelas e realizadas as porcentagens simples. Ainda com os dados obtidos, foi realizada estatística descritiva destes, no intuito de diagnosticar a real situação das UPLs avaliadas em relação aos critérios de biosseguridade animal.

\section{RESULTADOS E DISCUSSÃO}

As 22 granjas analisadas constituem um total de 22.220 matrizes produtivas a campo, o que representa um alojamento mensal de aproximadamente 50.000 leitões nas unidades terminadoras. Estes dados demonstram a grande importância econômica e social da atividade para os municípios da Região Noroeste do Rio Grande do Sul. A criação de suínos na região é favorecida, principalmente, pela aceitação do regime de integração associada e a estrutura fundiária, que por ser composta de pequenas propriedades facilita o modo de produção contratual (COLETTI \& LINS 2011). A Tabela 1 apresenta os dados de classificação das unidades produtoras conforme escala e sistema de produção de suínos nas granjas pesquisadas.

Entre as 22 granjas estudadas, nove delas (40,9\%) possuíam até 2.800 fêmeas em produção, enquanto que oito $(36,4 \%)$ granjas possuíam até 540 fêmeas. Essa distribuição representa o formato do arranjo produtivo utilizado na região pelas empresas parceiras que exigem de seus produtores integrados elevada produtividade para abastecimento tanto do mercado interno, como externo. Porém, este modelo de produção requer atenção com a sanidade do rebanho, uma vez que a divisão em sítios (verticalização), além de profissionalizar uma área específica, exige maior movimentação dos animais. De acordo com BRANDT (2008) este modelo de produção desafia a efetividade das barreiras sanitárias.

Tabela 1 - Classificação das unidades produtoras conforme a escala e sistema de produção.

Table 1 - Classification of the producing units conforming to the scale and production system.

\begin{tabular}{ccc}
\hline Classificação & $\mathrm{N}^{\mathrm{o}}$ de Granjas & $\%$ \\
\hline & Escala de produção & 36,4 \\
\hline Até 540 matrizes & 08 & 22,7 \\
541 a 1000 matrizes & 05 & 40,9 \\
1001 a 2800 matrizes & 09 & 100,0 \\
\hline Total & 22 & 27,3 \\
\hline UPD & 06 & 72,7 \\
\hline UPL & 16 & 100,0
\end{tabular}

UPD - unidade produtora leitões desmamados com até $7 \mathrm{~kg}$; UPL - unidade produtora leitões descrechados com até $23 \mathrm{~kg})$. 
Conforme a Tabela 1, destaca-se a predominância de leitões descrechados $(72,7 \%)$ nas unidades produtoras que realizam o manejo de condução até o animal atingir $23 \mathrm{~kg}$. Os animais com peso superior são transferidos para o produtor de terminação com o intuito de aumentar a imunidade, facilitar a adaptação e garantir-lhes a sobrevivência até a fase de abate.

Dentro do contexto da biosseguridade animal, a Tabela 2 apresenta a classificação das unidades produtoras conforme a condição básica para acesso interno a área da granja. Pela condição de acesso as granjas, evidencia-se (Tabela 2) que $72,7 \%$ das propriedades estudadas atendem o requisito de isolamento da área limítrofe com cerca, assim como $86,4 \%$ das granjas possuem a guarita como local específico para a troca de roupas e acesso interno.

A existência da cerca de isolamento e vestiário são componentes essenciais para o bom andamento dos programas de Biosseguridade, pois inibem e restringem o livre acesso de veículos, pessoas e outros animais nas áreas de produção. Desta forma, essas medidas auxiliam o controle e a transmissão de doenças infecciosas aos suínos (BARCELLOS et al. 2008) como, por exemplo, a diarréia epidêmica suína (WILLIAMSON et al. 2013).

Também se verificou que $40,9 \%$ das granjas não disponibilizam roupa específica para funcionários e visitantes, o que pode representar uma rota de contaminação tanto para os animais quanto para as pessoas que ali circulam. Outra informação de extrema relevância, é que apenas $22,7 \%$ das granjas realizam a prática do banho no acesso às instalações produtivas, apesar de muitas possuírem as estruturas físicas necessárias para tal. Contudo, BORGES et al. (2011) destacam que as medidas de higiene aplicadas aos visitantes da granja são de suma importância, uma vez que todos que ali circulam são potenciais fontes de transmissão de patógenos.

A entrada de patógenos pode ocorrer tanto de maneira direta pela introdução de novos animais na granja, como também de maneira indireta, através de aerossóis (OBERLENDER et al. 2013). BARCELLOS et al. (2008) destacam que a transmissão de microrganismos pelos aerossóis em granjas nos meses mais quentes e secos é menor, em

Tabela 2 - Classificação das unidades produtoras conforme a condição básica para acesso interno a área da granja.

Table 2 - Classification of the producing units according to the basic condition for internal access the area of the farm.

\begin{tabular}{ccc}
\hline Classificação & $\mathrm{N}^{0}$ de Granjas & $\%$ \\
\hline Atende & Cerca de isolamento & 72,7 \\
Não atende & 16 & 27,3 \\
\hline Total & 6 & 100,0 \\
\hline & 22 & 86,4 \\
\hline Atende & Guarita & 13,6 \\
Não atende & 19 & 100,0 \\
\hline Total & 03 & 59,1 \\
\hline & 22 & 40,9 \\
\hline Atende & Uniforme & 100,0 \\
Não atende & 13 & \\
\hline Total & 09 & 22,7 \\
\hline Atende & 22 & 77,3 \\
\hline Não atende & Banho & 100,0 \\
\hline Total & 05 &
\end{tabular}


virtude do ressecamento das partículas de aerossóis e, consequentemente, morte dos agentes infecciosos. Já no período de inverno, em função da alta umidade e redução da radiação ultravioleta, a transmissão de aerossóis é mais acentuada, podendo, em determinados casos, alguns vírus alcançarem até $20 \mathrm{~km}$ de distância por meio das correntes de vento.

Outro ponto avaliado foi à necessidade de informações sobre as diversas operações que ocorrem rotineiramente nas granjas (Tabela 3). O correto processo de embarque e desembarque de animais é atendido por $90,9 \%$ das granjas avaliadas. Já o recebimento de ração e retirada dos dejetos sem necessidade de acesso a área interna da granja foi evidenciada em $86,4 \%$ e $95,4 \%$ das propriedades, respectivamente (Tabela 3). Cabe destacar que o transporte entre granjas e até os frigoríficos também afeta a Biosseguridade dos animais, seja pela exposição a organismos patogênicos ou pelos hematomas resultantes de choques físicos (DALLA COSTA et al. 2007).

Com relação a descarga de ração, a condição ideal é que o silo para recebimento seja instalado na parte interna da granja, paralelo à cerca de isolamento, e que a descarga seja feita com caminhão graneleiro através da área externa (SESTI 2003), pois o transporte até a granja e o caminho para a disponibilização da ração também podem configurar rotas de contaminação (FOSSE et al. 2009).

No que se refere à remoção do material orgânico da composteira, verificou-se que em $68,2 \%$ das propriedades, o veículo que retira o composto para espalhar na lavoura não necessita entrar na área da granja. $\mathrm{O}$ restante das propriedades $(31,8 \%)$ também executam o manejo, mas não possuem composteira próxima a área limítrofe.

Outro elemento primordial na condução de uma atividade agropecuária é a fonte de água utilizada para a dessedentação dos suínos. Pode-se verificar que em $54,5 \%$ das propriedades o abastecimento de água para os animais é realizado com poço artesiano, seguido por afloramento de água subterrânea associada ao poço artesiano em $22,7 \%$ das propriedades, conforme demanda (Tabela 4). Nesse sentido, PADILHA et al. (2013) destaca que a adoção de medidas de desinfecção, como cloração da água servida aos animais, é uma forma de eliminação dos microrganismos capazes de gerar infecções.

Apesar da importância da cloração da água servida aos animais, evidenciou-se que esta não é uma prática adotada nas propriedades analisadas, uma vez que apenas $27,3 \%$ das unidades utilizam o método. Este percentual está diretamente relacionado ao fato de que a maioria dos produtores acredita não haver a necessidade de desinfecção por tratar-se de água de poço artesiano. Contudo, BORGES et al. (2011) ressalta a necessidade de realização de análises físico-químicas e microbiológicas da água para a determinação do tratamento adequado a utilização desejada.

Outro aspecto importante para a biosseguridade de suínos refere-se ao controle de vetores que deve ocorrer de forma sistemática, sendo incorporado a rotina da granja. De acordo com o Manual de Procedimentos Sanitários (SIPS 2012), o controle de roedores, moscas e outros insetos, são essenciais para minimização das transmissões de enfermidades.

De acordo com o estudo realizado por AGUILAR et al. (2015), os vetores se tornam transmissores de doenças, principalmente, pelo contato com as fezes. Nesse estudo os autores verificaram que os principais agentes transmissores de doenças envolvem a Escherichia coli, Brachyspira spp., Salmonella spp. e Streptococcus spp., sendo a E. coli, uma das maiores causadoras de doenças na suinocultura (SILVA et al. 2015).

Como alternativa para reduzir a disseminação de vetores, podem ser observados alguns aspectos como: local para instalação da granja, aspectos construtivos, controle de tráfego de veículos e materiais, controle do fluxo de pessoas, conhecimento da origem de animais para reposição de plantel, cuidados com o transporte dos animais, e também o manejo adequado de resíduos, e de animais mortos.

Outra possibilidade para o controle de moscas é a ação integrada através da manutenção da propriedade limpa e organizada, sem presença de entulhos. Deve-se realizar a eliminação de focos de procriação, cuidado especial às lagoas de armazenamento de dejetos, uso de controle químico ou biológico e eliminação do foco em alguma fase do seu ciclo (FOSSE et al. 2009).

A atual forma de conduzir a atividade de produção de suínos faz uso da criação intensiva e sistemática.

Esta condição por sua vez, proporciona ganhos interessantes, mas por outro lado, desafia o equilíbrio sanitário, pois a maior concentração de animais pode acarretar maior difusão de doenças infecciosas (TOLEDANO 2015). 
Tabela 3 - Classificação das unidades produtoras conforme a realização do fluxo de transporte externo a área da granja.

Table 3 - Classification of the producing units as the accomplishment of the transport flow expresses the area of the farm.

\begin{tabular}{ccc}
\hline Classificação & $\mathrm{N}^{\mathbf{o}}$ de Granjas & $\%$ \\
\hline Atende & Embarcadouro & 90,9 \\
Não atende & 20 & 9,1 \\
Total & 02 & 100,0 \\
\hline & 22 & \\
\hline Atende & Recebimento ração & 86,4 \\
Não atende & 19 & 13,6 \\
Total & 03 & 100,0 \\
\hline Atende & 22 & 95,4 \\
Não atende & 21 & 4,5 \\
Total & 01 & 100,0 \\
\hline Atende & 22 & 68,2 \\
Não atende & Retirada de dejetos & 31,8 \\
Total & 07 & 100,0 \\
\hline
\end{tabular}

Tabela 4 - Classificação das unidades produtoras conforme a origem da água de bebida fornecida aos animais. Table 4 - Classification of the producing units as to the origin of the drink water supplied the animals.

\begin{tabular}{ccc}
\hline Classificação & $\mathrm{N}^{0}$ de Granjas & $\%$ \\
\hline Poço artesiano & 12 & 54,5 \\
Fonte protegida & 03 & 13,6 \\
Ambas & 05 & 22,7 \\
Três ou mais origens & 02 & 9,1 \\
\hline Total & 22 & 100,0 \\
\hline Realiza & Cloração da água & \\
Não realiza & 06 & 72,7 \\
\hline Total & 16 & 100,0 \\
\hline
\end{tabular}


Outro fator que deve ser destacado é a falta de conhecimento do custo benefício em se aplicar medidas de biosseguridade nas propriedades. LAANEN et al. (2014) apontaram este fator como limitante para investimentos e motivação dos produtores de suínos. Em um trabalho realizado em granjas de aves de postura, LAGATTA (2014) calculou que as medidas de biosseguridade representavam cerca de $1,9 \%$ do custo total da produção da caixa de ovos.

Portanto, fica evidente a necessidade de se explorar ações que promovam melhorias no sistema de produção de suínos e, consequentemente, que possam minimizar os riscos de enfermidades em populações de animais.

\section{CONCLUSÃO}

Os municípios da Região Noroeste do Rio Grande do Sul se destacam como grandes produtores de suínos no regime de integração, apresentando esta atividade uma grande importância econômica e social.

A maioria das UPLs avaliadas na Região Noroeste atende aos principais requisitos de Biosseguridade estabelecidos pela Instrução Normativa n.19 (MAPA 2002). Contudo, alguns pontos críticos foram observados, tais como a baixa adoção de cloração da água utilizada na dessedentação dos animais, baixa adoção da prática do banho e roupas específicas para funcionários e visitantes no momento da entrada na granja, bem como a necessidade de adoção do arco de desinfecção em unidades produtivas onde, atualmente, o sistema de embarque dos animais é realizado na área interna da granja, e não no limite.

A aplicação do questionário desenvolvido pelo MAPA (2002) é uma ferramenta importante e que permitiu a obtenção de resultados, os quais poderão nortear, adaptar e aperfeiçoar a adoção de práticas de biosseguridade nas granjas produtoras de suínos.

\section{REFERÊNCIAS}

AGUILAR CEG et al. 2015. Implementação e avaliação das práticas de biosseguridade na produção de suínos. Uma revisão. Revista Brasileira de Higiene e Sanidade Animal 9: 320-333.

BARCELLOS DESN et al. 2008. Avanços em programas de biosseguridade para a suinocultura. Acta Scientiae Veterinariae 36: 33-46.

BORGES SRT et al. 2011. Avaliação dos níveis de biosseguridade das granjas de reprodutores suínos certificadas do Estado de São Paulo, Brasil. Veterinária e Zootecnia 18: 417-431.

BRANDÃO FS. 2013. Tendências para o consumo de carne bovina no Brasil. Tese (Doutorado em Agronegócios). Porto Alegre: UFRGS. 101p.

BRANDT G. 2008. Quarto Sítio seria a melhor solução para incorporação de matrizes de reposição em um rebanho suíno. Acta Scientiae Veterinariae 36: 137-142.

COLETTI T \& LINS HN. 2011. A suinocultura no vértice das relações entre agroindústria e agricultura familiar no oeste de Santa Catarina. Ensaios FEE 32: 339-360.

DALLA COSTA OA et al. 2007. Effects of the season of the year, truck type and location on truck on skin bruises and meat quality in pigs. Livestock Science 107: 29-36.

FAO - Food and Agriculture Organization of the United Nations. 2015. Organização das Nações Unidas para a Alimentação e a Agricultura. Combate à fome. Disponível em: https://www.fao.org.br/cf.asp. Acesso em: 02 nov. 2015.

FOSSE J et al. 2009. Prevalence and risk factors for bacterial food-borne zoonotic hazards in slaughter pigs: a review. Zoonoses and Public Health 56: 429-454.

IBGE - Instituto Brasileiro de Geografia e Estatística. 2012. Censo Agropecuário 2012. Disponível em: http:// www.sidra.ibge.gov.br/bda/pecua/default.asp. Acesso em: 4 out. 2015.

LAANEN M et al. 2014. Pig, cattle and poultry farmers with a known interest in research have comparable perspectives on disease prevention and on-farm biosecurity. Preventive Veterinary Medicine 115: 1-9.

LAGATTA L. 2014. Impacto socioeconômico das políticas sanitárias sobre os estabelecimentos avícolas comerciais de postura da regional agropecuária de Limeira, Estado de São Paulo. Dissertação (Mestrado em Ciências). Pirassununga: USP. 99p.

MASCARENHAS LA et al. 2015. Produção de suínos com vazio sanitário. Interdisciplinar: Revista Eletrônica da UNIVAR 14: 23-28.

MAROTO MARTÍN LO et al. 2010. Bacterial contamination of boar semen affects the litter size. Animal Reproduction Science 120: 95-104.

MIELE M \& WAQUIL PD. 2007. Cadeia produtiva da carne suína no Brasil. Revista de Política Agrícola 16: 7587.

MAPA - Ministério da Agricultura, Pecuária e Abastecimento. 2002. Instrução Normativa/DAS n.19, de 15 fev. 2002. Normas para a Certificação de Granjas de Reprodutores Suídeos. Diário Oficial da União, Poder Executivo (DF).

OBERLENDER $G$ et al. 2013. Bacteriologia do sêmen suíno - aspectos relacionados: revisão de literatura. Revista Científica Eletrônica de Medicina Veterinária 20: 1-15.

OCDE-FAO. 2015. Perspectivas agrícolas 20152024. Disponível em: http://www.agri-outlook.org/ specialfeature/. Acesso em: 08 nov. 2015. 
PADILHA ACM et al. 2013. Análise do uso de água tratada na produção de suínos. Revista Agropecuária Técnica 34: 50-60.

POETA APS et al. 2014. Panorama da suinocultura no Rio Grande do Sul. Porto Alegre: Secretaria da Agricultura, Pecuária e Irrigação. 11p. (Informativo Técnico 7).

SESTI LAC. 2003. Biosseguridade na produção de suínos: Plano de contingência para granjas GRSC. In: $11^{\circ}$ Congresso Brasileiro de Veterinários Especialistas em Suínos. Resumos... Goiânia: ABRAVES. p.136-147.

SIPS - Sindicato das Indústrias de Produtos Suínos. 2010. Manual de procedimentos sanitários para a suinocultura. Disponível em: https:// www.sips.com.br/download.php. Acesso em: 10 out. 2015.

SILVA CVO et al. 2015. Escherichia coli na suinocultura. Aspectos clínicos. Uma Revisão. Revista Brasileira de Higiene e Sanidade Animal 9: 288-293.

SONCINI RA \& SCHEID IR. 2008. Auditorias em biosseguridade em granjas de suínos. Acta Scientiae Veterinariae 36: 47-51.

TOLEDANO F. 2015. Sanidade Animal: A sanidade no foco das discussões. Disponível em: http://www. diadecampo.com.br/zpublisher/materias/Materia. asp? $\mathrm{id}=21533 \&$ secao=Sanidade 20 Animal. Acesso em: 08 nov. 2015.

WILLIAMSON S et al. 2013. Emergence of Porcine Epidemic Diarrhoea in pigs in the USA. Veterinary Record 173: $146-148$. 